\title{
EFFECTS OF ORGANIC MANURES AND INORGANIC FERTILIZERS ON GROWTH, YIELD AND SHELF LIFE OF TOMATO (LYCOPERSICON ESCULENTUM MILL.)
}

\author{
Sameena Sadiq* and Suchi Modi \\ Department of Biotany, School of Biological Sciences \\ Rabindranath Tagore University, MP, India
}

Received: 10.02.2021

Revised: 20.02.2021

Accepted: 05.03.2021

\begin{abstract}
The present investigation entitled "Effect of Organic manure and Inorganic fertilizers on growth, yield and shelf life of tomato (Lycopersicon esculentum Mill.) was conducted during the kharif season 2020 to assess the effects of inorganic and organic fertilizers on growth parameters, yield attributes and shelf life of tomato variety Pusa Ruby. The experiment was laid in a rendomized block design (RBD) with 8 treatments each replicated thrice.The treatments consisted of different levels of organic fertilizers and inorganic fertilizers. The treatments used were $\mathrm{T}_{1}$ Control (with no fertilizer), $\mathrm{T}_{2}-100 \%$ NPK RDF (120:80:60), $\mathrm{T}_{3}-100 \%$ CD @20t/ha, $\mathrm{T}_{4}-100 \%$ VC @20t/ha, $\mathrm{T}_{5}-75 \%$ NPK + 25\% CD @5t/ha, $\mathrm{T}_{6}-50 \% \mathrm{NPK}+50 \% \mathrm{CD} @ 10 \mathrm{t} / \mathrm{ha}, \mathrm{T}_{7}-75 \% \mathrm{NPK}+25 \% \mathrm{VC} @ 5 \mathrm{t} / \mathrm{ha}, \mathrm{T}_{8}-50 \% \mathrm{NPK}+50 \% \mathrm{VC}$ @10t/ha. Among 8 treatments, treatment $\mathrm{T}_{8}(50 \% \mathrm{NPK}+50 \% \mathrm{VC})$ recorded maximum height $(74.30 \mathrm{~cm})$, maximum number of branches (9.8), maximum number of flowers/cluster (7.8), minimum days to first fruiting (49.6 days), maximum number of fruits/cluster (6.4), maximum number of fruits per plant (19), maximum weight per fruit (68.86), maximum yield per plant (1.42) and maximum shelf life (11). However, treatment $\mathrm{T}_{4}-100 \%$ VC showed minimum days to $50 \%$ flowering (39.8) and maximum number of flower cluster per plant (14.8). Thus, it could be concluded that the use of combination of organic and inorganic fertilizers has potential in improving growth, fruit yield and shelf life of the tomato Pusa Ruby.
\end{abstract}

Keywords: Tomato, Pusa Ruby, Cattle dung, Vermicompost, RDF.

\section{INTRODUCTION}

Horticulture is a branch of agriculture concerned with cultivation, production and sale of various crop plants. Horticulture crops include fruits, vegetables, nuts, spices, condiments, mushrooms, and ornamental plants, medicinal and aromatic plants. L.H. Bailey is considered as the Father of American Horticulture and M.H. Marigowda is considered as the Father of Indian Horticulture. Horticulture crops are a source of dietary fibres, vitamins, minerals, nutrients, flavour, aroma etc. This sector enables the population to eat a diverse and balanced diet. Horticulture crops serve as raw materials for various industries viz., confectionery, oils and paints, perfumery and cosmetics, processing, pharmaceutical, etc.
Tomato production has been faced by many challenges in most countries. Framers use heavy doses of pesticides and chemical fertilizers in order to get better yield. The continuous application of these chemical fertilizers and pesticides decreases the soil fertility by increasing the concentration of heavy metals in the soil. Also, many poor farmers cannot buy high yielding varieties as they are expensive. Meanwhile, the price of fertilizers increases, year by year, due to the higher amount of fertilizers needed in the second and third seasons as compared with that in the first season to maintain the current yield production at economical level. (Selim. M., 2020). Farmers, in the developing countries having low level of education and insufficient training regarding proper agricultural practices is another reason for the low production of crops. Inorganic

*Corresponding author: sameenasadiqwani@gmail.com 
fertilizers, also known as mineral or chemical fertilizers, have high level of nutrients and these nutrients are released quickly as there is no need of decomposition. As a result, inorganic fertilizers result in increased yield. However, there are many disadvantages in using inorganic fertilizers for a long time. These are destruction of soil texture and structure, which leads to soil erosion and increased acidity as a result of leaching. Besides, inorganic fertilizers are costly and pose negative effects on environment if managed improperly. Organic fertilizers, on the other hand, maintain the quality of soil by improving biological activity, structure and chemistry of soil. They are known to increase soil organic matter content by gradually releasing the nutrients. However, decomposition of organic material is strongly affected by temperature and soil moisture. This means that nutrients may be released continuously even when the plants do not need them. Also, organic fertilizers are low in nutrient content and not all organic materials are available in many regions, these fertilizers alone do not meet the nutrient requirements of the crop. Tomato is heavy yielder and hence requires sufficient fertilizers for growth and high yield. Because of the high cost of purchasing inorganic fertilizers and inadequate nutrient content in organic fertilizers, some farmers use a mixture of organic and inorganic fertilizers. Various studies have revealed that the combination of organic and inorganic fertilizers proven to be effective in increasing productivity and soil fertility has also been increased in an integrated manner. The present study was conducted to investigate the "Effect of organic manures and inorganic fertilizers on the growth, yield, yield attributes and shelf life of tomato (Lycopersicon esculentum Mill.)". The study was conducted during kharif season 2020.

\section{MATERIALS AND METHODOLOGY}

The experiment was conducted with the seeds of the tomato cultivar Pusa Ruby. It is an early maturing variety. Plants are indeterminate. It is suitable for cultivation during autumn, winter and spring-summer seasons. It is a high yielding variety. The fruits are flattish round, small medium and red. The fruits have a good market value. The experiment was laid out in a randomized block design (RBD). There were a total of 8 treatments and each treatment was replicated three times. So, there were a total of 24 plots. The size of the plot taken was $2 \mathrm{~m} \times 1.8 \mathrm{~m}$. All the treatments were randomized separately in each replication. Raised nursery bed of 3 metres length and 1 metre width was prepared. The bed was made with a fine tilth and properly pulverized and solarised. Seeds were sown in the furrows about $2 \mathrm{~cm}$ deep and $8 \mathrm{~cm}$ apart. Only healthy and disease free seeds are used. After the sowing of seeds, the seed bed was covered with FYM and then watered. Nursery bed was regularly irrigated during evening hours.3.2.3 Preparation of experimental plots. The experimental field was prepared by deep ploughing to a fine tilth by repeated harrowing and levelling. After ploughing, the field was laid out according to the layout and the plots were prepared. Before the removal of seedlings, the nursery bed was properly irrigated to avoid injury and damage to the roots while pulling the seedlings. Recommended dose of inorganic fertilizer like N (Urea), P2O5 (Single Super Phosphate) and K2O (Muriate of Potash) were added to the respective plots. Half dose of nitrogen and full dose of potassium and phosphorus were applied at the time of transplanting where, the remaining dose of $\mathrm{N}$ is given after 30 days and 60 days of transplanting. The organic fertilizers applied were cattle dung and vermicompost. Cattle dung was given at the rate of 5 and 10 t/ha whereas, vermicompost was added at the rate of 5 and 10 t/ha. Each organic fertilizer was given in the allocated plots. The fertilizers were mixed well by ploughing.

The heights of all the tagged plants were measured using a centimetre scale. The height was measured from the base of the main stem to the apex of the plants. Plant height was measured from 30 days of planting up to 90 days to observe the growth rate of plants. The average of five plants was calculated and recorded for each treatment.

The number of branches was counted from 30 days of planting up to 90 days when the plants had ceased to grow. The total number of branches per plant was recorded from the sampled and tagged plants from each plot and the mean was computed.

The number of days taken from the date of transplanting to the opening of first flower in 50\% population under each treatment was recorded as days to $50 \%$ flowering. Number of flower cluster per plant was taken from five tagged plants during the flowering season and the average value was calculated and recorded. The number of flowers per cluster was recorded from the five sampled plants under each treatment and the mean value was calculated. Number of flower per cluster were calculated for 5 plants.

\section{RESULTS}

The growth characters i.e. plant height and number of branches was significantly influenced by different treatments over control. Plant height and number of branches increased with the advancement of plant growth. Plant height and number of branches per plant was recorded at regular intervals from 30 DAT to 90 DAT. The maximum plant height was 74.30 recorded with the treatment T8$50 \%$ NPK $+50 \%$ VC. The second best treatment was T7$75 \%$ NPK + 25\% VC. Both the treatments were significantly superior to the rest of the treatments. Also, the number of branches per plant was recorded maximum with the treatment T8- 50\% NPK + 50\% VC that showed 9.8 branches. The second best treatment was T7-75\% NPK + $25 \%$ VC showed 8.7.The different treatment combinations 
have significantly influenced on days to 50\% flowering and the number of flower clusters per plant. The minimum number of days taken to 50 flowering was obtained by treatment $\mathrm{T} 4-100 \%$ VC showed 39.8 days to $50 \%$ flowering followed by treatments T8- 50\%NPK + 50\%VC and $\mathrm{T} 7-75 \% \mathrm{NPK}+25 \% \mathrm{VC}$ showed 40.4 and 41.2 days to $50 \%$ flowering respectively. Also, the number of flower clusters per plant was maximum in treatment T4-100\% VC i.e. 14.8 flower cluster per plant. The second best treatment was T8- 50\% NPK + 50\% VC followed by treatment T7$75 \%$ NPK $+25 \%$ VC showed 14 and 13.4 respectively.The maximum number of flowers per cluster was recorded highest in treatment T8- 50\% NPK + 50\% VC showed 7.8 number of flowers per cluster and T7- 75\% NPK + 25\% VC produced 7 number of flowers per cluster. Different treatments significantly influenced the number of days taken to first fruiting. Treatment T8- 50\% NPK + 50\% VC took minimum number of days i.e. 49.6 to first fruit setting.

\section{DISCUSSION AND CONCLUSION}

The present study revealed that plant growth characters i.e., plant height and number of branches per plant gradually increased with the age of the plant. Plant height and number of branches is the indicator of growth and vigour of the plant. The height and number of branches per plant was taken at regular intervals. The data revealed that the height and number of branches were significantly influenced by the application of different combinations of organic manures and inorganic fertilizers. The maximum height $74.30 \mathrm{~cm}$ and number of branches 9.8 was recorded by treatment T8-50\% NPK + 50\% VC followed by T7- 75\% $\mathrm{NPK}+25 \% \mathrm{VC}$. Increased growth parameters might be due the organic manures applied in combination with NPK fertilizer. This might be due to the fact that organic manures have supplied additional amount of nutrients both micro and macro nutrients and have improved the soil physical and chemical properties. Also, many of the nutrients in vermicompost are changed to their available forms in order to make them easily utilizable by plants. Similar findings were recorded by Wang et. al. (2017), Eswaran and Mariselvi (2016), Chanda et. al. (2011) and others. It was also observed that the least increase in height and number of branches was recorded by treatment T1 (control with no fertilizer). It showed the importance of fertilizers for growth of the plant.

The present study revealed that plant growth characters i.e., plant height and number of branches per plant gradually increased with the age of the plant. Plant height and number of branches is the indicator of growth and vigour of the plant. The height and number of branches per plant was taken at regular intervals. The data revealed that the height and number of branches were significantly influenced by the application of different combinations of organic manures and inorganic fertilizers. The maximum height $74.30 \mathrm{~cm}$ and number of branches 9.8 was recorded by treatment T8-50\% NPK + 50\% VC followed by T7- 75\% $\mathrm{NPK}+25 \% \mathrm{VC}$. Increased growth parameters might be due the organic manures applied in combination with NPK fertilizer. This might be due to the fact that organic manures have supplied additional amount of nutrients both micro and macro nutrients and have improved the soil physical and chemical properties. Also, many of the nutrients in vermicompost are changed to their available forms in order to make them easily utilizable by plants. Similar findings were recorded by Wang et. al. (2017), Eswaran and Mariselvi (2016), Chanda et. al. (2011) and others. It was also observed that the least increase in height and number of branches was recorded by treatment $\mathrm{T} 1$ (control with no fertilizer). It showed the importance of fertilizers for growth of the plant.

\section{REFERENCES}

1. Selim, M. M. (2020). Introduction to the integrated nutrient management strategies and their contribution to yield and soil properties. International journal of agronomy. 2821678:1-14.

2. Xin-Xin Wang, Zhao, F., Zhang, G., Zhang, Y. and Yang, L. (2017). Vermicompost improves tomato yield and quality and the biochemical properties of soils with different tomato planting history in a greenhouse study. Frontiers in plant science. 8: 1-11.

3. Chanda, K.G., Bhunia, G. And Chakraborty, K.S. (2011). The effect of vermicompost and other fertilizers on cultivation of tomato plants. Journal of horticulture and forestry. 3(2): 42-45.

4. Eswaran, N. and Mariselvi, S. (2016). Efficacy of vermicompost on growth and yield parameters of Lycopersicon esculentum (Tomato). International journal of scientific and research publications. 6(1): 95-108.

5. Islam, M.R., Chowdhury, M.A.H., Saha, B.K. and Hasan, M.M. (2013). Integrated nutrient management on soil fertility, growth and yield of tomato. Journal of Bangladesh agricultural university. 11(1): 33-40.

6. Horticulture statistics division. 2018. Department of agriculture, cooperation and farmers welfare. 